\title{
СПЕЦИФИКА ОРГАНИЗАЦИИ КОНТРОЛЯ УСВОЕНИЯ УМЕНИЙ ГОВОРЕНИЯ
}

\section{SPECIFICITY OF ORGANIZING CONTROL OF MASTERING SPEAKING SKILLS}

K. Kramar

L. Milovanova

Summary: The purpose of this article is to determine an effective method for controlling the formation of speaking skills in high school. The article clarifies the stages of mastering speaking skills (reproductive, reproductive-productive and productive) and formulates control criteria for each of them. The scientific novelty of the research lies in the substantiation of the need to identify the reproductive-productive stage (due to the problem of the "silent student" - the lack of constructive feedback when teaching oral speech), as well as the substantiation of the need for step-by-step control, which is usually not taken into account by the compilers of textbooks on preparation for oral exams intended for high school students (in particular, training manuals for the exam). Based on the results of the experiment of the authors of the article, it is shown that one of the types of tasks that can serve as an effective means of control according to all criteria of the formation of speaking skills at a productive level is the final presentation of the group project work of high school students.

Keywords: speaking, foreign language, control, project work, speaking.

\author{
Крамар Камила Наильевна \\ Соискатель, Московский государственный \\ педагогический университет \\ kamillakramar@gmail.com \\ Милованова Людмила Анатольевна \\ Д.п.н., профессор, Московский государственный \\ педагогический университет \\ ludmilamilovanova@yandex.ru
}

Аннотация: Целью настоящей статьи является определение эффективного метода контроля сформированности умений говорения в старшей школе. В статье проясняются этапы усвоения умений говорения (репродуктивный, репродуктивно-продуктивный и продуктивный) и формулируются критерии контроля для каждого из них. Научная новизна исследования заключается в обосновании необходимости выделения репродуктивно-продуктивного этапа (в связи с проблемой "молчаливого ученика" - отсутствия конструктивной обратной связи при обучении устной речи), а также обосновании необходимости поэтапного контроля, что как правило не учитывается составителями пособий по подготовке к устным экзаменам, предназначенных для учащихся старших классов (в частности, пособий по подготовке к ЕГЭ). На материале результатов эксперимента авторов статьи показано, что одним из видов заданий, которое может служить эффективным средством контроля по всем критериям сформированности умений говорения на продуктивном уровне, является итоговая презентация групповой проектной работы старшеклассников.

Ключевые слова: говорение, иностранный язык, контроль, проектная работа, устная речь.

ресурсы преподавателя (количество занятий, объем упражнений) ограничены.

(2) Обучение говорению должно иметь коммуникативную направленность. Учебная ситуация должна быть похожа на ситуацию реального общения; используемые выражения должны быть оценены учеником (и преподавателем) с точки зрения естественности употребления [7]. Из четырех языковых навыков говорение предполагает максимальную ответственность - и, если учащиеся не играют активной роли в собственном обучении, оно не будет эффективным [10]. Но ученики существенно различаются по уровню подготовки и, что чаще всего взаимосвязано, по уровню мотивации, которая не всегда достаточна. А.Ю. и Г.С. Казанцевы выделяют следующие «демотиваторы» говорения: стеснение и страх ошибки, медленная скорость реакций, отсутствие интереса к обсуждаемой теме, недостаток языковых и речевых средств [3].

(3) Говорение предполагает навык неподготовленной речи. Ситуации диалога, позволяющие его выработать, 
характеризуются содержательной гибкостью - люди переключаются с темы на тему [7], а также отклонением от лекал «книжной» грамматики ради естественности и краткости. Диалог предполагает использование интонационных и невербальных средств. Таким образом, говорение - вид языковой деятельности, максимально требовательный к «soft skills» - способностям человека эффективно использовать всевозможные «техники", алгоритмы и знания: эмпатии, самоконтролю, способности рисковать, критически мыслить, адаптироваться к меняющемуся окружению и т.д. [11].

(4) Наконец, как отмечал выдающийся лингвист Е.И. Пассов, эффективное решение коммуникативной задачи всегда предполагает избыточность задействованных языковых средств. Согласно философской герменевтике, коммуникация - это соприкосновение мировоззрений и культур, а «survival language», языковая «аптечка», обеспечивающая только передачу необходимого минимума сведений, по словам Пассова, «отличается от умения вести диалог культур, как нож дикаря от лазерных приборов современной хирургии» [5]. О том же пишет и Т.А. Сенькова, показывая, что считать классический «топик» точкой отсчета, разделяя его далее на ситуации, «методически неверно» при обучении говорить [7], поскольку ситуация не тематична, а содержательна.

Резюмируем. Язык функционирует при взаимодействии двух видов знаний - собственно языковых и энциклопедических, описывающих внеязыковой мир. Как писала И.Л. Бим, «чем ярче впечатление, произведенное словом, чем значительнее ситуация, в которой оно встречалось, чем больше в нем потребность, тем лучше оно запоминается» [2]. Преподавание иностранного языка нуждается в обновлении, поскольку основано еще на старой «механической» модели обучения говорению как «жесткому» навыку. Это же обстоятельство предопределяет, во-первых, необходимость реализовывать обучение говорению на научной основе, а во-вторых - необходимость разработки технологии обучения с учетом вышеобозначенных сложностей. Технология обучения как «знание того, как обучать» [6] предполагает и методику измерения результата.

Целью настоящей работы является эскизное изложение такой методики применительно к говорению на иностранном языке. При этом мы предполагаем, что измерение может производиться по-разному на разных стадиях овладения говорением. Цель предполагает следующие задачи: во-первых, будут выделены этапы контроля сформированности умения говорить; во-вторых, в соответствии с ними будут представлены критерии контроля; в-третьих, будут кратко представлены результаты эксперимента, посвященного обоснованию целесообразности групповой проектной работы учащихся старших классов как средства контроля.

Для решения данных задач использованы следующие методы: сравнительный анализ источников - трудов педагогов-методистов, а также пособий по подготовке к ЕГЭ по иностранному языку, общенаучные методы (индукция, дедукция, анализ, синтез), эксперимент и статистические методы для интерпретации его результатов. Теоретической базой исследования являются работы отечественных педагогов-лингвистов - Е.И. Пассова, А.Н. Щукина, И.Л. Бим, а также отечественные и зарубежные публикации, посвященные проблемам обучения говорению на иностранном языке. Практическая значимость работы состоит в том, что предложенные критерии оценки сформированности умений говорения могут быть использованы в педагогической деятельности, а также при составлении пособий для подготовки к устным экзаменам и экзаменационных материалов.

\section{Контроль умений говорения в старшей школе: этапы и критерии.}

Этапы контроля сформированности умения - это временные интервалы, в которых задачи и способы контроля различаются.

А.Н. Щукин пишет о двух этапах формирования умений говорения: введении (презентации) и активизации «умений использовать слова и словосочетания для построения высказываний, при восприятии сообщений, использование лексики в речевом общении» [9]. Е.А. Пассов пишет о репродуктивном и продуктивном этапах: сперва человек овладевает языковыми единицами, которые можно использовать в готовом виде, на втором этапе познает композициональность языка - учится создавать потенциально бесконечные значащие последовательности языковых единиц. Первый этап задействует преимущественно память, второй - аналитические способности. Овладение композициональностью нивелирует фактор новизны в говорении: «достигается такое умение путем постоянного варьирования речевыми ситуациями, путем замены в речевой ситуации каждый раз какого-то нового компонента ... Это нужно для того, чтобы подготовиться к общению в адекватных условиях» [5]. Финальный результат - формирование языкового чутья (Пассов называет это «эвристичностью общения» - способностью контекста «подсказывать» подходящие средства выражения мыслей, позволяя говорить без усилий).

Далее мы воспользуемся терминологией Пассова, добавив переходный этап - репродуктивно-продуктивный уровень. Репродуктивное обучение подразумевает преимущественную активность учителя, продуктивное творческую работу ученика; однако способность ученика давать обратную связь учителю - тоже навык, не 
дающийся готовым. Необходимость его сформировать (особенно в контексте обозначенной выше проблемы «молчаливого ученика») в процессе обучения говорению и определяет необходимость выделения промежуточного этапа.

Три этапа овладения языком приводят к тому, что учащийся способен решить коммуникативную задачу в реалистичных условиях. Соответственно, правильно подобранные задания на говорение должны «создавать внутреннюю потребность к общению» [3], что, вероятно, сложнее всего обеспечить. Во всяком случае, обратная связь ученика и преподавателя является маркером того, что овладение коммуникацией на иностранном языке связано для первого с познавательной деятельностью и личностными ценностями. Соблюдая вышеназванные этапы и оценивая усвоение умений говорения на каждом, преподаватель постепенно подготавливает учеников к собственному, спонтанному высказыванию на тему, релевантную коммуникативной ситуации.

Рассмотрим каждый из этапов, а также специфику организации контроля усвоения умений говорения на каждом из них.

Сущностью репродуктивного этапа, как можно предположить по названию, является повторение. На этой теме особо останавливается Е.И. Пассов: расхожее мнение о том, что язык - это «много зубрежки», отчасти верно, но повторение не является самоцелью. Ученик «должен быть поставлен перед необходимостью не имитировать, конструировать, репродуцировать и т.п., а совершать речевой поступок» [5]; процедуры имитации, когда учитель предоставляет готовые языковые средства, являются только первоначальным этапом обучения. По этой причине, по словам Пассова, повторение ранее изученных слов и выражений не должно выноситься в отдельную часть урока, поскольку в этом случае теряется его мотивированность. Распределенное повторение, во-первых, занимает меньше времени, а вовторых, стимулирует учащегося создавать «обобщенную модель речевого образца» [5], поскольку повторяемая единица используется для решения разных коммуникативных задач.

Критерием прохождения репродуктивного этапа формирования умений говорения является способность передать основное содержание прочитанного/ услышанного (идею и сюжет текста, ключевые детали) и делать умозаключения относительно него. Вариантами упражнений, развивающих репродуктивную речь, могут быть задания на пересказ близко к тексту, ответы на вопросы по тексту, сформулированные в соответствии с его логикой, подстановка слов и выражений в текст, а также поиск ответов на специальные вопросы. Возможным типом задания является текст с «пропуска- ми», где некоторые слова заменены на русские. Ученику следует подыскать стратегию выражения недостающего смысла: использовать слово с близким или более общим значением, заменить его описанием или определением предмета, попробовать передать содержание при помощи невербальных средств или даже попросить (на изучаемом языке) помощи у кого-то другого. Задание на чтение текста вслух, также репродуктивное, призвано обеспечить формирование фонетических навыков. Репродуктивны задания-игры с карточками, больше подходящие для младшей школы (например, когда требуется дать правильное название изображенному или совершить определенное действие).

Сущность репродуктивно-продуктивного этапа конструктивная обратная связь, т.е. совершение коммуникативных действий, направленных на улучшение других коммуникативных действий. На этом этапе учащиеся вовлекаются в диалог с преподавателем и друг с другом. Критерии прохождения этого этапа применительно к диалогической речи, на наш взгляд, следующие: учащийся должен уметь запрашивать информацию в рамках изученных тем и обмениваться ею с другими участниками диалога, а также быть способным обратиться за разъяснениями, уточнить необходимую информацию. На репродуктивно-продуктивном этапе получают развитие общие, используемые безотносительно родного или иностранного языка умения - перемещение между разными аспектами темы, способность слушать собеседника, включаться в дискуссию, задавать вопросы, выражать согласие/несогласие. Одна из главных задач репродуктивно-продуктивного этапа как переходного - снять мотивационные барьеры, позволить ученикам проявлять себя в диалоге, не боясь неизбежных ошибок [3].

Если мы говорим о монологической речи, критерием прохождения репродуктивно-продуктивного этапа является построение высказываний с опорой на ключевые слова, план или вопросник. Учащимся необходимы умения выделять главную информацию в тексте и при необходимости игнорировать второстепенную, догадываться о значении неизвестного, находить необходимую информацию в текстах разного жанра и стиля, узнавать в текстах полезные речевые единицы. Замечания Е.И. Пассова о необходимости «расширения синтагм» - постепенного увеличения коммуникативных единиц путем добавления новых слов к готовым клише также относятся к репродуктивно-продуктивной стадии [5]. Возможные упражнения для репродуктивно-продуктивного этапа в популярных пособиях - это коммуникативно-ориентированные игры, подразумевающие исполнение определенных социальных ролей [3], задания на описание изображений или пересказ с опорой на них, импровизированные интервью, составление презентаций на иностранном языке и т.д. Учащийся, способный 
поддерживать диалог, используя сложные конструкции без существенных ошибок, описывать опорный материал и задавать уточняющие вопросы, обладает сформированными умениями говорения на репродуктивнопродуктивном уровне.

Можно видеть, что некоторые задания затрагивают два уровня сразу: таким является упомянутое упражнение, где предлагается заменить русские слова иностранными или использовать иную стратегию. Тем не менее мы подчеркиваем необходимую этапность работы педагога. Она обеспечивает «связь выработки автоматизма с мыслительной деятельностью» [5], реализуя принцип «от простого к сложному», при этом сохраняя ориентацию на цель говорения - речевой поступок.

Продуктивный этап подразумевает самостоятельное конструирование речевых единиц произвольной сложности, выбор релевантных средств общения и, наконец, речевую импровизацию. Эти способности позволяют проявить творческое начало и «в конечном счете определяют умение общаться» [5]. Предлагаемые нами критерии для продуктивного уровня: способность вести диалог/полилог в ситуациях неофициального общения в рамках изученной тематики и формулировать несложные связные высказывания с использованием основных типов речи (описание, рассуждение, характеристика) в рамках заданной темы. Для оценки сформированности умений говорения на продуктивном уровне как высокой требуется уметь подробно отвечать на поставленные вопросы, используя сложные конструкции, уместным образом «входить» в беседу и «выходить» из нее, подробно описывать предложенный предмет или рассуждать о нем.

При этом в большинстве популярных пособий для старшеклассников заданий, развивающих и контролирующих именно продуктивную речь, немного - или они представлены как дополнительные. Например, это упражнения на диалог-расспрос, составление монологов или задания с элементами речевой импровизации (когда ученику допускается в диалоге сменить тему на смежную, подтвердить или опровергнуть мнение собеседника с опорой на личный опыт или опыт знакомых). Это отчасти объяснимо тем, что продуктивный этап как «продвинутый» предполагает максимально свободную устную речь учеников. Как отмечают А.Ю. и Г.С. КазанцеВы, составление упражнений на говорение должно «обеспечивать не только действие, но и взаимодействие» [3], при этом, как отмечалось выше, учебная аудитория как правило разномастная в плане уровня владения устной речью и общими коммуникативными навыками. Для решения этой проблемы авторы предлагают работать по возможности в малых группах (т.к. проще осуществлять контроль); проводить мозговые штурмы при выборе темы; отдельно, до выполнения дискуссионных заданий обсуждать тему с учениками, которые не включаются в диалог по психологическим причинам; как можно чаще повторять ключевые слова.

В целом, для пособий для подготовки к ЕГЭ (например, Андрощук Н.А., Баскакова В.Н. Английский язык. Practise speaking. М.: Титул, 2022 или Сафонова В.В., Бутенкова Е.В., Зуева П.А. ЕГЭ-2021. Английский язык. Сборник заданий. 400 заданий с ответами. М.: Эксмо-Пресс, 2020) характерны следующие типы заданий: ответы на вопросы по тексту, пересказ близко к тексту, поиск ответов на специальные вопросы с целью усвоения и систематизации лексико-синтаксических средств внутри и межфразовой связи предложений в монологе (репродуктивный уровень); передача основного содержания текста по плану и без опоры на план, восстановление текста в логической последовательности из разрозненных предложений, продолжение рассказа, окончание истории и т.п., соединение предложений в разных колонках с целью получения связного высказывания (репродуктивно-продуктивный); монологи по проблемным вопросам с привлечением пройденного материала (продуктивный). Поскольку устная часть ЕГЭ призвана проверить базовые умения говорения, представляется целесообразным проверять лишь базовые умения диалога, а заданием высокой сложности должен стать монолог.

\section{Проектная работа как элемент контроля.}

С нашей точки зрения, перспективным типом задания (а также формой контроля усвоения умений говорения) может стать групповая проектная работа. В некоторых источниках ([8], [1]) существенно тот же вид заданий обозначается как case-study. Несмотря на распространение концепций диалогической педагогики, доминирующим сценарием при обучении говорить является т.н. «декламационный»: учитель объясняет и задает закрытые вопросы, ученики дают краткие ответы, учитель осуществляет минимальную обратную связь, выставляя отметки. Лишь изредка его вопросы помогают ученику сформулировать более разносторонний или менее стандартный ответ. Декламационный сценарий означает, что фактически оценивается соответствие сказанного учеником тому, что думает услышать учитель. Средняя продолжительность диалога учителя и ученика составляет всего 5 секунд [10]. Такая ущербная модель учебного говорения распространена повсеместно.

Одним из средств противодействия и видится проектная работа. Согласно определению А.Ю. и Г.С. Казанцевых, это «самостоятельно планируемые и реализуемые студентами работы, в которых речевое общение вплетено в интеллектуально-эмоциональный контекст другой деятельности» [3]. Преимущество проектной работы в том, что она позволяет оценить такие важные умения, как умение выступать с монологом, отвечать 
на вопросы по содержанию выступления, уточнять их и вносить дополнения. Очевидно, что они относятся к продуктивному уровню и требуют серьезной языковой подготовки. В качестве критериев оценивания презентации выделяют следующие умения: лексико-грамматические, аналитические (логичность и последовательность рассуждений, отбор и анализ информации), организационные (активность, навыки коллективной работы и тайм-менеджмента) и презентационные (релевантность презентации, умение задавать вопросы и давать ответы) [4].

На преподавателя ложится непростая задача организации работы и формирования эффективных рабочих групп. Об этом достаточно подробно пишет Е.И. Пассов. Помимо уровня языковой подготовки среди критериев организации рабочей группы он отмечает учебные и внеучебные интересы учеников, их взаимоотношения, популярность в классе, эмоциональный склад и умение общаться, работоспособность и т.д. Данные по критериям можно получить путем опроса, а приоритет одного критерия над другим решается индивидуально. Важно лишь то, что отношения между участниками групп изначально должны быть положительными или нейтральными [5]. Группа, получив задание, выбирает исполнителей рабочих функций: например, если суть проекта - создание новостной передачи, нужно назначить редактора, ведущих, корреспондентов и т.д. [3]

На наш взгляд, проектная работа (точнее, ее устная презентация) может быть включена в итоговый контроль по разделу «Говорение». С целью проверки был проведен эксперимент (выборка 237 человек; 3 экспериментальных и 3 контрольных группы по уровню владения английским языком), включавший подготовку в экспериментальных группах проектных работ и последующее сопоставление результатов контроля умений говорения экспериментальных групп и контрольных групп (занимавшихся по «традиционной» методике). Было, в частности, отмечено превышение средней оценки на устной части мониторинга учащихся экспериментальных групп на 0,3 балла по сравнению с усредненной оценкой учащихся контрольных групп. Рейтинги, набранные старшеклассниками экспериментальной группы, с небольшим расхождением совпали с итоговыми рейтингами успеваемости, тогда как в контрольной группе в $15 \%$ случаев наблюдалось сильное расхождение. Последовавший опрос участников показал, что практически все $(97,6 \%)$ считают групповое обсуждение доклада самым эффективным способом обучения. Источником эффективности проектной работы является приближенность к реальной проблемной ситуации, из которой нет единственно правильного выхода, так что ученики вынуждены двигаться методом проб и ошибок, используя иностранный язык [1]. Проектная работа позволяет преодолеть страх перед говорением (отметили $56 \%$ опрошенных) и улучшает речь в целом (отметили 70,4\% опрошенных). Опрос учителей показал, что ученики стали заинтересованнее и ответственнее, стали лучше усваивать специфическую лексику (по сравнению с результатами домашнего чтения). Также опрошенные были единодушны относительно большей очевидности прогресса учеников и объективности оценки говорения на иностранном языке.

\section{Зак^ючение}

На основании сказанного можно сделать следующие выводы.

1. Усвоение умений говорения целесообразно представлять в виде трех уровней: репродуктивного, репродуктивно-продуктивного и продуктивного. На репродуктивно-продуктивном учащийся овладевает умением осуществлять конструктивную обратную связь на иностранном языке, что подготавливает его к более творческим задачам.

2. Обучение говорению и контроль усвоения соответствующих умений должны соотноситься с выделенными этапами (в связи с чем выделены 6 критериев по уровням), что, к сожалению, чаще всего не реализуется в учебных пособиях. Не все критерии проверяются, а задания продуктивного уровня обычно являются дополнительными или отсутствуют. Чаще всего обучение говорению сводится к декламационному сценарию, сводящему на нет творчество учащихся.

3. В рамках контроля целесообразно учитывать устную презентацию проектных работ учащихся. Согласно проведенному эксперименту, оценка за проект имеет сильную корреляцию с оценкой за устную часть итогового экзамена, позволяя достаточно объективно судить о владении устной речью, потому данный вид контроля может быть использован и как дополнение к традиционным, и как альтернатива им.

\section{ЛИТЕРАТУРА}

1. Асташенко А.И., Павлова Л.В. Особенности обучения говорению с использованием метода кейсов на занятиях по английскому языку // Интерактивная наука. 2016. №10

2. Бим И.Л. Методика обучения иностранным языкам как наука и проблемы школьного учебника. М.: Русский язык, 1977 
3. Казанцев А.Ю., Казанцева Г.С. Эффективность обучения говорению на английском языке в высшей школе // Вестник ТГПУ. 2014. №3 (144).

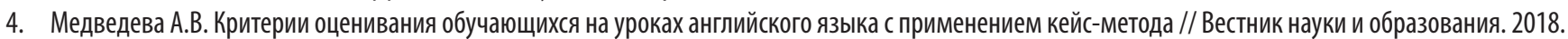
№6 (42).

5. Пассов Е.И., Кузовлева Н.Е. Основы коммуникативной теории и технологии иноязычного образования. М.: Издательство "Русский язык", 2010

6. Рогова Г.В., Верещагина И.Н. Методика обучения английскому языку на начальном этапе в средней школе — М.: Просвещение, 1988.

7. Сенькова Т.А. Методика формирования речевых навыков и основные принципы обучения говорению на иностранном языке // Труды БГТУ. Серия 6: История, философия. 2014. №5 (169).

8. Хитарова Т.А. Обучение говорению на иностранном языке в системе высшего образования // Colloquium-journal. 2019. №28 (52).

9. Щукин А.Н. Теория обучения иностранным языкам (лингводидактические основы). М.: ВК, 2012.

10. Hardman F., Abd-Kadir J. Classroom discourse: towards a dialogic pedagogy // Wyse D., Andrews R., Hoffman J. The Routledge International Handbook of English, Language and Literacy Teaching. NY: Routledge, 2010

11. Klaus P. The Hard Truth About Soft Skills. London, Harper Collins Publishers Ltd, 2008

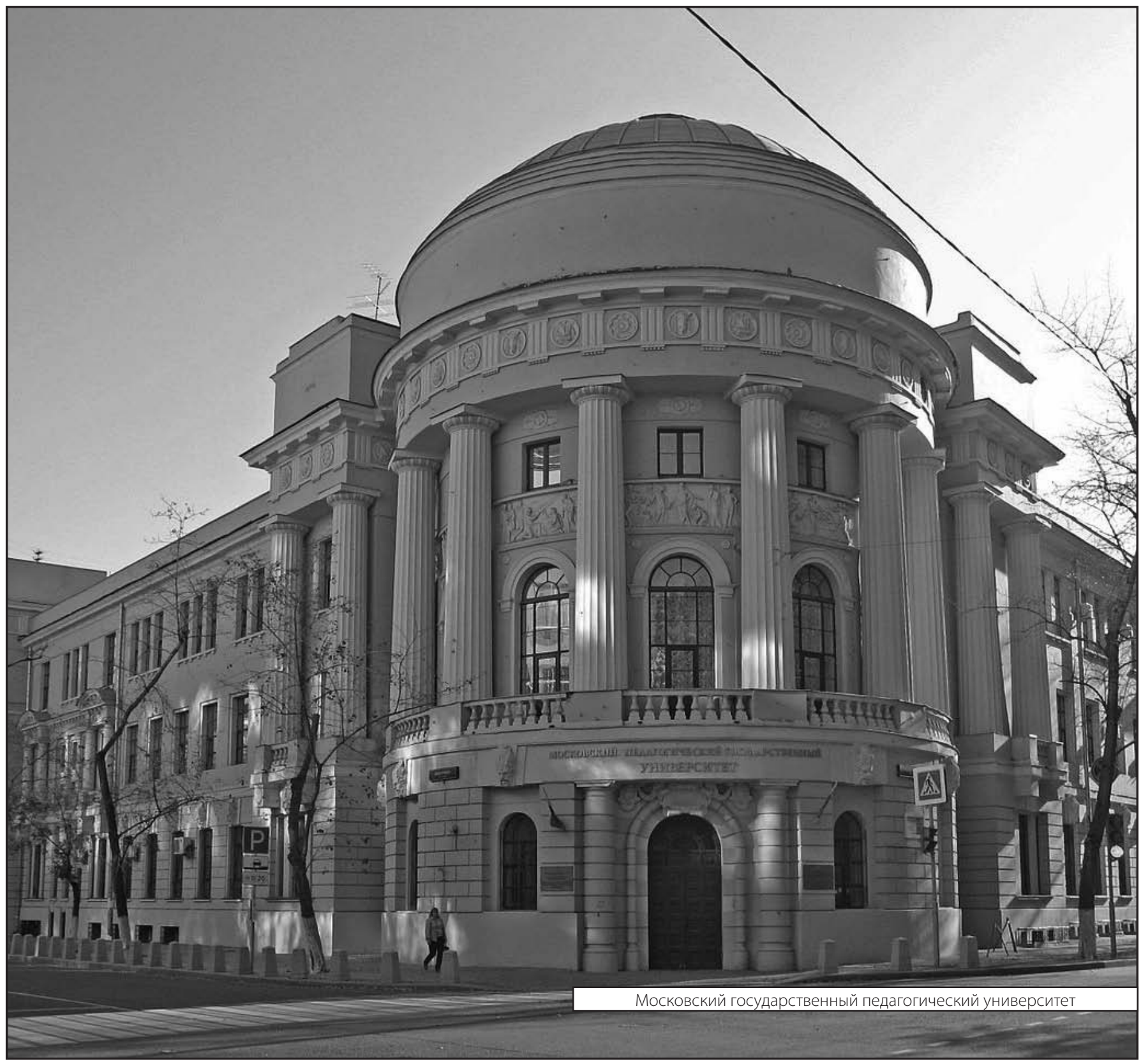

